\title{
Performance of a Solar Chimney for Cooling Building Façades under Different Heat Source Distributions in the Air Channel
}

\author{
Y Quoc Nguyen ${ }^{\mathrm{a}, 1}$, Sa Nguyen-Tan ${ }^{\mathrm{a}}$, Hong-Tham T. Pham ${ }^{\mathrm{b}, 2}$, Ai Manh-Thuy ${ }^{\mathrm{a}}$, Trieu Huynh-Nhat ${ }^{\mathrm{a}}$ \\ ${ }^{a}$ Faculty of Engineering, Van Lang University, Ho Chi Minh City, Vietnam \\ ${ }^{b}$ Faculty of Civil Engineering, Ho Chi Minh City University of Technology, Ho Chi Minh City, Vietnam \\ Corresponding author: ${ }^{1} y . n q @ v l u . e d u . v n,{ }^{2}$ Ptham0825@gmail.com
}

\begin{abstract}
Solar chimneys can be employed in buildings for natural ventilation, cooling, or heating of the building envelope, hence saving energy. In open double-skin facades, the air channel's thermal effects between the two layers of a façade are similar to those in a solar chimney. Most studies about solar chimney in the literature have been focusing on heating one air channel wall. In this study, the performance of a solar chimney under different distributions of the heat source on both walls of the air channel was studied numerically by the Computational Fluid Dynamics method. Induced flow rate, temperature rise, and thermal efficiency of the chimney were investigated. Chimneys with practical dimensions with the height ranging from $0.5 \mathrm{~m}$ to $1.5 \mathrm{~m}$ and the gap-to-height ratio ranging from 0.025 to 0.15 were examined. The results showed that together with the chimney's dimensions, location, and distribution of the heat source on the channel's walls strongly affect the performance of the chimney. While heating the whole left wall induced more flowrate than heating the whole right wall, heating part of the left and the right walls resulted in peak performance at specific portions of the right wall heated from the bottom or the top of the channel. The peak values of the investigated parameters and the specific portions of the heated wall to achieve those peaks also changed with the channel's gap-to-height ratio.
\end{abstract}

Keywords - Solar chimney; natural ventilation; building façade; heat source; CFD

\section{INTRODUCTION}

Among the methods for controlling solar heat gain of buildings to save energy, double - skin façade (DSF) has been proved to be effective [1]-[3]. Quahtan [3], studying the thermal performance of a double-skin façade of a building in Malaysia, reported that the maximum temperature difference of indoor-outdoor temperature was up to $6^{\circ} \mathrm{C}$ for a un-airconditioned space. In Qatar, a DSF covering $40 \%$ of the walls could reduce $11.3 \%$ of the building's total heat gain [2].

The air cavity inside a DSF can be closed or opened [1], [4]. When the cavity is opened, absorbed solar radiation heats the air in the cavity and induces thermal or stack effect, a wellknown phenomenon in solar chimneys [5]. Therefore, results from solar chimneys studies can be applied to DSFs with similar configurations [4].

Several studies about solar chimneys have been reported, as summarized by Saadatian et al. [6] and Shi et al. [7]. Most of them focused on examining factors influencing solar chimneys' performance [8]-[17]. The factors have been reported in two major groups: structural and environmental
[7]. The structural group's main parameters were the chimney's dimensions, including the width of the cavity, the air gap, and the air channel's height. Solar radiation seemed to be the most critical environmental factor. Also, previous studies [17], [18] also reported that the distribution of the heat source inside the air channel also affected the performance of solar chimneys. Their results showed that heating one side or both sides of the air channel could significantly change the induced airflow rate. However, in previous research, the heat source was distributed on a whole wall of the channel. Cases where the heat source distributes on a portion of the channel's walls, have not yet been reported.

In this study, a solar chimney's performance with the heat source distributing on a portion of each air channel wall was studied numerically. The performance was assessed through three main parameters: the induced flow rate, the temperature rises through the air channel, and the thermal efficiency of the chimney. 


\section{MATERIAL AND METHOD}

\section{A. Problem Description}

The studied problem is sketched in Figure 1. A building is assumed to have a two-layer wall; the inner layer can be a concrete wall, while the outer one can be a glazed or opaque plate. In the case of a glazed wall, solar radiation is transmitted through the glazing and absorbed by the inner wall. For the other case, the outer wall is an opaque plate such as a metal sheet. It is heated by solar radiation. In either case, the absorbed heat is transferred to the air inside the gap through natural convection. If the façade has open ends, an airflow is induced due to the warmed air's thermal effects. The airflow may help to reduce the solar heat gain, hence cooling the façade.

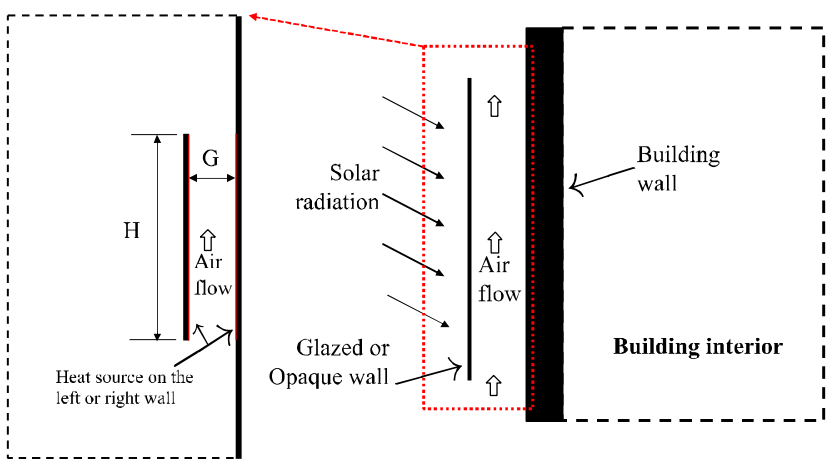

a) Modeled solar chimney (Elcvation vicw)

b) Cooling effects in double facades

Fig. 1 Schematic of natural convection flow in a double façade and according to the modeled solar chimney

It is assumed that the dimension of the façade, which is normal to the plane in Figure 1, is larger than the gap of the cavity between the two layers of the wall. Consequently, the cavity can be modeled as a two-dimensional solar chimney [18], shown in Figure 1. The channel gap and height are denoted as $\mathrm{G}$ and $\mathrm{H}$, respectively. The chimney is attached to a vertical wall that models the inner wall of the building. Heat source on either side of the wall is described by applying uniform heat flux on the inner surface of the air channel of the chimney. In the case of a glazed outer wall, the heat flux is assigned on the air channel's right wall in Figure 1. However, for an opaque outer wall, the heat flux should be assigned on the air channel's left wall. For intermediate cases where part of the outer wall is glazed while the remaining is opaque, the modelled heat source should be applied according to portions of both the left and the right wall of the air channel, as described in Figure 2.

\section{B. Governing Equations}

The governing equations for the airflow and heat transport in the solar chimney include conservations of continuity, momentum, and energy. The airflow and heat transfer were assumed to be steady. The flow was incompressible. Using the two-dimensional Reynolds Averaged Navier - Stokes (RANS) equations, the governing equations are as follows $[18,19,20]$ :

$$
\begin{gathered}
\frac{\partial U_{j}}{\partial x_{j}}=0 \\
\frac{\partial\left(U_{i} U_{j}\right)}{\partial x_{j}}=-\frac{1}{\rho} \frac{\partial P}{\partial x_{i}}-g_{i} \beta\left(T-T_{r e f}\right)+\frac{\partial}{\partial x_{j}}\left(v \frac{\partial U_{i}}{\partial x_{j}}-\overline{u_{i} u_{j}}\right)(2) \\
\frac{\partial\left(T U_{j}\right)}{\partial x_{j}}=\frac{\partial}{\partial x_{j}}\left(\frac{v}{P r \frac{\partial T}{\partial x_{j}} \overline{T^{\prime} u_{j}}}()\right)
\end{gathered}
$$

Where $\mathrm{i}$ and $\mathrm{j}$ indices denoting the horizontal and vertical directions; $\mathrm{U}, \mathrm{u}$ and $\mathrm{T}, \mathrm{T}$ ' are respectively time-averaged and fluctuating velocities, and time-averaged and fluctuating temperatures; $\mathrm{T}_{\text {ref }}$ is the reference temperature taken as the ambient one; $\mathrm{P}$ is the pressure; $\rho$ and $v$ are the air density and kinematic viscosity; $\beta$ is the air thermal expansion coefficient; $\mathrm{Pr}$ is the Prantl number, indicates a time-averaged quantity. In equation (2), the Boussinesq approximation was applied for the variation of the air density with temperature, as suggested in previous studies [18], [20], [21].

For the turbulent stress $\overline{u_{i} u_{j}}$ and turbulent heat flux $\overline{T^{\prime} u_{j}}$, typical RANS turbulence models such as standard $k-\omega, k-\omega$ with modifications for low-Reynolds-number effects (low-Re $k-\omega$ ), $k-\varepsilon$, and RNG $k-\varepsilon$ [22] can perform well for this problem $[18,20]$.
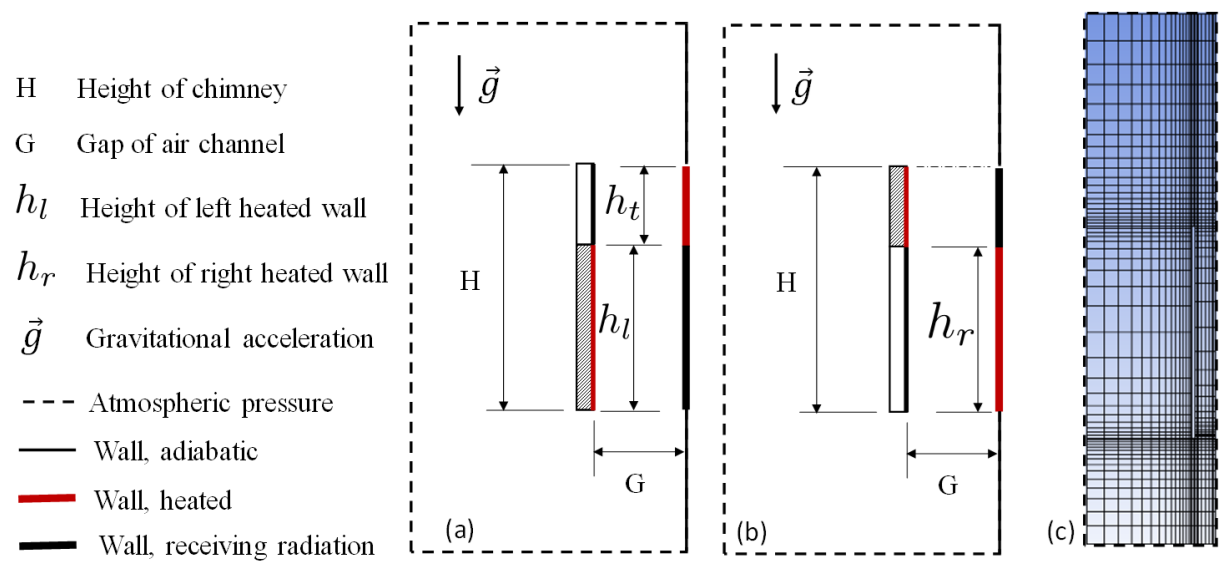

Fig. 2 Computational domain and boundary conditions for two cases of heating location: (a) on the left wall and (b) on the right wall; and (c) mesh structure

In this study, four models were applied to predict the induced flow rate through a solar chimney in the experiment by Yilmaz and Fraser [23], the low-Re $k-\omega$ offered the best convergence rate and the best agreement between the computed flow rate and the measurements, as seen in Figure 3. Therefore, it was selected. 
The governing equations, Equation (1)-(3) was discretized on a structured mesh, as shown in Figure 2c, using Finite Volume Method with the ANSYS Fluent CFD code (Academic version 2019R3). For the coupling between the continuity equation and the momentum equation, the SIMPLEC method [19] was employed.

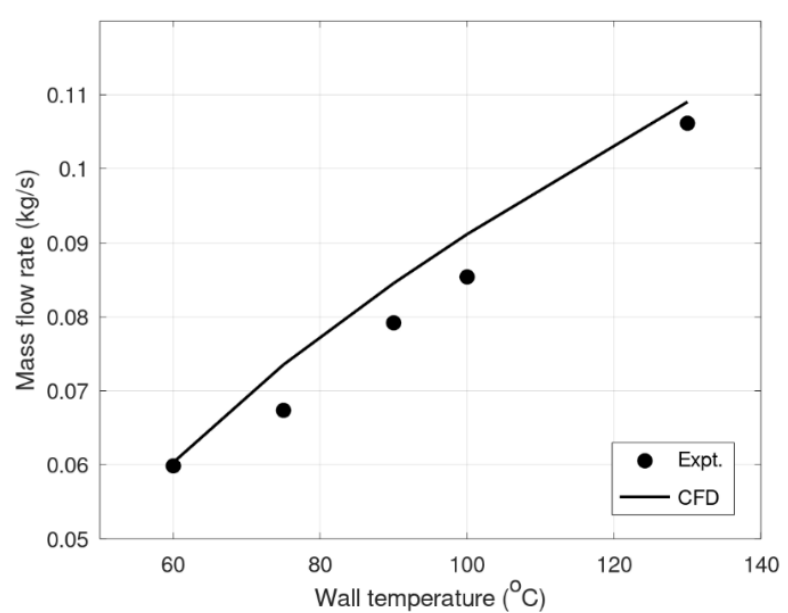

Fig. 3 Comparison of the induced flow rate obtained with the CFD model versus the experimental values by Yilmaz and Fraser [23]

\section{Computational Domain and Boundary Conditions}

The computational domain is described in Figure $2 \mathrm{a}$ and $2 \mathrm{~b}$. It covered both the air channel and the ambient air. The extension of the air channel's domain is necessary to allow the airflow to adapt to local flow conditions at the inlet and outlet of the air channel [18]. Following the suggestions by Gan [18], the extensions of the domain in Figure 2 were $10.0 \times \mathrm{G}$ above, $5.0 \times \mathrm{G}$ below, and 5.0 x G to the left of the air channel. Larger domains were also tested. It was seen that the induced flow rate changed less than $0.5 \%$ as the domain was further enlarged.

As the right side of the domain in Figure $2 a$ and $2 b$ coincided with the building wall (Figure 1a), it was modeled as a non-slip wall. Other boundaries of the domain were assigned with atmospheric pressure, as they were open. For simplicity, heat conduction through the outer wall of the chimney was not modeled. The surfaces of the outer wall were applied with no-slip conditions. Inside the air channel, only the left and the right walls participated in the heat transfer. Generally, part of the outer wall may be either glazed or opaque, while the remaining had the opposite optical property. Assumed that the lower portion of the left wall, whose length is $h_{l}$, was opaque, uniform heat flux condition was applied on $h_{l}$. As the upper part of the left wall was glazed, the solar radiation should be absorbed by the upper part of the right wall over a length of $h_{t}=H-h_{l}$. Accordingly, uniform heat flux condition was applied on the portion $h_{t}$ of the right wall. Similarly, $h_{r}$ denotes the right wall's length with uniform heat flux for a glazed portion of $h_{r}$ of the left wall. The remaining upper part of the left wall $\left(H-h_{r}\right)$ was assigned with heat flux.

Radiative heat transfer between the left and the right walls of the air channel was allowed in the model. The process was calculated by the S2S model in the ANSYS Fluent software [24]. A non-uniform structured rectangular mesh was used as presented in Fig. 2c. The mesh was clustered near the solid boundaries, particularly the air channel's heated walls, and higher mesh densities were also distributed at the inlet and outlet of the air channel.

To check the mesh-independence, the CFD model was run with the solar chimney tested by Yilmaz and Fraser [23] with $\mathrm{H}=3.0 \mathrm{~m}$ and $\mathrm{G}=0.1 \mathrm{~m}$ and a heat flux of $360.3 \mathrm{~W} / \mathrm{m}^{2}$. Different mesh resolutions were employed to obtain the induced mass flow rate through the channel. It was observed that, as the number of mesh elements increased, the flow rate changed below $1.0 \%$ when the maximum non-dimensional distance of the first grid point from the solid boundaries, or $\mathrm{y}^{+}$, was less than 2.0. This number was equivalent to 150 and 200 cells in the $\mathrm{G}$ and $\mathrm{H}$ directions inside the air channel. This required value of $\mathrm{y}^{+}$was close to the findings by Zamora and Kaiser [20], which was below 1.0.

\section{Validation}

The CFD model was validated against the measurements by Yilmaz and Fraser [23]. In their experiments, the induced flow rate was measured through a solar chimney with $\mathrm{H}=3.0$ $\mathrm{m}, \mathrm{G}=0.1 \mathrm{~m}$, and the third dimension of $1.0 \mathrm{~m}$. Various heat fluxes were applied on one side of the air channel, and according to wall temperatures were from $60^{\circ} \mathrm{C}$ to $130^{\circ} \mathrm{C}$. The measured and computed induced flow rates were plotted together in Figure 3, as functions of the wall temperature. The maximum discrepancy between the two results was $9.2 \%$. Therefore, the model can reproduce well the measured data.

\section{RESULTS AND DISCUSSIONS}

The validated CFD model was employed to predict the induced flow rate, temperature rise through the chimney described in Figure 1a, and its thermal efficiency. These parameters were examined as the following factors changed: Location of the heat source, i.e., on the left or the right wall; length of the heat source: $h_{r}$ and $h_{t}$; chimney height $\mathrm{H}=0.5 \mathrm{~m}$, $1.0 \mathrm{~m}$, and $1.5 \mathrm{~m}$; and the gap-to-height ratio $\mathrm{G} / \mathrm{H}=0.025$, $0.05,0.075,0.1$ and 0.15 . The applied heat flux was kept to $600 \mathrm{~W} / \mathrm{m}^{2}$ in all tests.

\section{A. Flow Rate}

The induced flow rate through the solar chimneys with different heights and gap-to-height ratios is presented in Figure 4 as the functions of the normalized length of the heated portion of the right wall, $h_{r} / H$ or $h_{t} / H$. As $h_{r}$ and $h_{t}$ denote the heated portions of the air channel's right wall from the bottom and the top, respectively, $h_{r} / \mathrm{H}=0$ or $h_{t} / H=0$ indicates that the whole left wall is heated. In contrast, for $h_{r} / H=1.0$ or $h_{t} / H=1.0$, the whole right wall is heated. For intermediate values of $h_{r} / H$ or $h_{t} / H$, both walls are heated at according to portions as sketched in Figure $2 \mathrm{a}$ and $2 \mathrm{~b}$.

The results in Figure 4 show that the induced flow rate increased with the gap, for a given chimney height $\mathrm{H}$, and either case of heating. The flow rate also increased with the chimney height. These trends have also been reported in the literature [17], [18], [21], [25].

At the gap-to-height ratio $(\mathrm{G} / \mathrm{H})$ of 0.025 , the flow rates obtained with $h_{r}$ and $h_{t}$ were indistinguishable from each other. However, as $\mathrm{G} / \mathrm{H}$ increased, the difference became more visible. In both heating cases, the flow rate increased with $\mathrm{hr}$ and ht, achieved a peak, and then decreased. Although the difference between the two maximum flow rates was minor, the peaks' positions were different. The peaks were at $h_{r} / H \approx$ 
0.2 and $h_{t} / H \approx 0.7$, for heating the right wall from the bottom and the top, respectively. The two flow rates matched at $h_{r} / H$ $=h_{t} / H \approx[0.35-0.4]$.

For the cases of heating the whole left wall $\left(h_{r} / H=h_{t} / H=\right.$ $0)$ or the whole right wall $\left(h_{r} / H=h_{t} / H=1.0\right)$, the results in Figure 4 show that heating the whole left wall induced more flow rate. The difference was more significant as the $\mathrm{G} / \mathrm{H}$ ratio increased. Nguyen and Wells [17] reported similar results in studying the induced flow rate through a solar chimney attached to a vertical wall. However, this trend is different from the results for a stand-alone vertical solar chimney [18]. Gan [18] showed that heating one side of the channel induced less flowrate than when both sides of the channel were heated with the same total heat flux.

The flow fields together with the temperature distributions for the chimney with $\mathrm{H}=0.5 \mathrm{~m}, \mathrm{G} / \mathrm{H}=0.025$ and $0.15, h_{r} / H=$ $h_{t} / H=0.8$ are shown in Figure 5. For $\mathrm{G} / \mathrm{H}=0.025$, the temperature and velocity fields were similar for both cases of heating. The thermal boundary layer expanded from the heated surfaces and occupied the whole channel gap at the outlet. Accordingly, the induced flow rates were identical, about $0.053 \mathrm{~kg} / \mathrm{s}$, as seen in Figure $4 \mathrm{a}$. For $\mathrm{G} / \mathrm{H}=0.15$, the thermal boundary layer near the right wall was thicker for $h_{r} / H=0.8$, while that near the left wall had a higher temperature. The temperature rise at the air channel outlet was
$10.3 \mathrm{~K}$ and $9.0 \mathrm{~K}$ for $h_{r} / H=0.8$ (Figure 5c) and $h_{t} / H=0.8$ (Figure 5d), respectively. As a result, the induced flow rate for $h_{r} / H=0.8$ was higher, as seen in Figure 4.

\section{B. Temperature Rise through the Chimney}

As the air in the channel receives heat from the walls, its temperature rises. The temperature rise is defined as follows:

$$
\Delta T=T_{o}-T_{i}
$$

Ti and To are the air temperature at the inlet (bottom) and the air channel's outlet (top).

The temperature rise through the examined chimneys is plotted in Figure 6. For each $\mathrm{H}$, the highest temperature rise was seen at the lowest gap-to-height ratio, $\mathrm{G} / \mathrm{H}=0.025$. At all heights, $\Delta T$ decreased as $\mathrm{G} / \mathrm{H}$ increased. This observation is opposite to that of the flow rate in Figure 4.

It is seen that at large $\mathrm{G} / \mathrm{H}$ ratios $(\mathrm{G} / \mathrm{H}=0.15$ and 0.1$)$, heating the right wall from the top $\left(h_{t}\right)$ yielded a higher temperature rise. As $\mathrm{G} / \mathrm{H}$ became smaller, heating the right wall from the bottom $\left(h_{r}\right)$ tended to produce higher $\Delta T$ at the lower range of $h_{r} / H$ or $h_{t} / H$. The point where the same $\Delta T$ values obtained with both heating cases gradually moved to the right $\left(h_{r} / H\right.$ or $\left.h_{t} / H \rightarrow 1.0\right)$. Until $\mathrm{H}=0.5 \mathrm{~m}$ and $\mathrm{G} / \mathrm{H}=0.025$, heating from the bottom (hr) resulted in an entirely higher temperature rise.

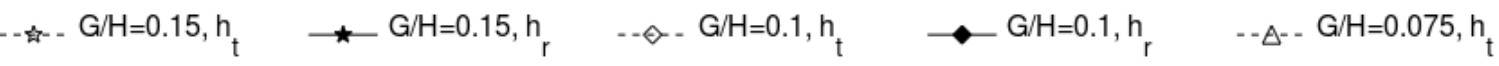

$$
\begin{aligned}
& \neg \mathrm{G} / \mathrm{H}=0.075 \mathrm{~h}_{\mathrm{r}} \quad--\boxminus-\mathrm{G} / \mathrm{H}=0.05, \mathrm{~h}_{\mathrm{t}} \quad-\mathrm{G} / \mathrm{H}=0.05, \mathrm{~h}_{\mathrm{r}} \quad--\odot-\mathrm{G} / \mathrm{H}=0.025, \mathrm{~h}_{\mathrm{t}} \longrightarrow \mathrm{G} / \mathrm{H}=0.025, \mathrm{~h}_{\mathrm{r}}
\end{aligned}
$$

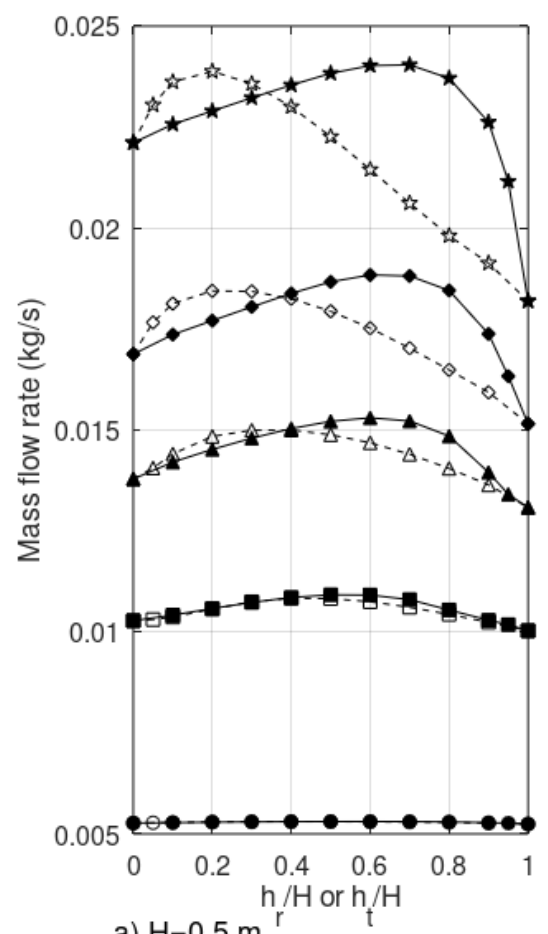

a) $\mathrm{H}=0.5 \mathrm{~m}^{\mathrm{r}}$

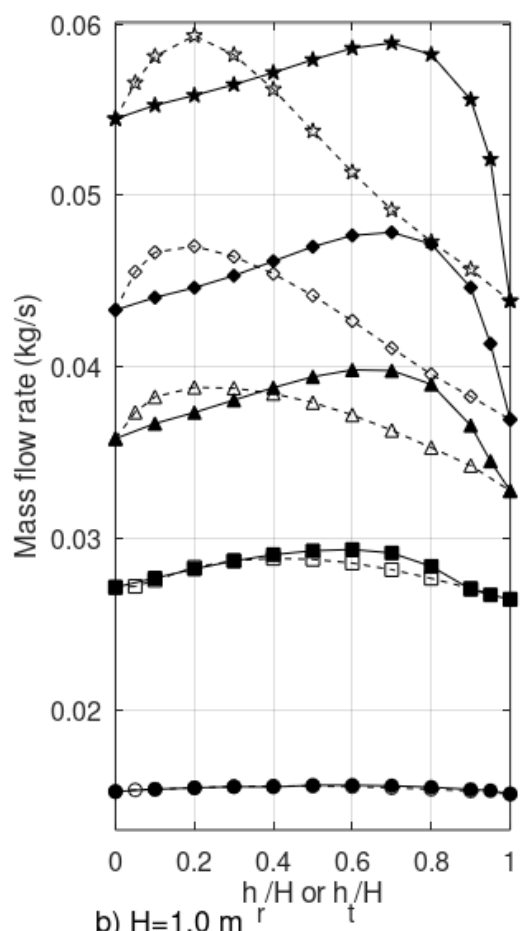

b) $\mathrm{H}=1.0 \mathrm{~m}^{\mathrm{r}}$

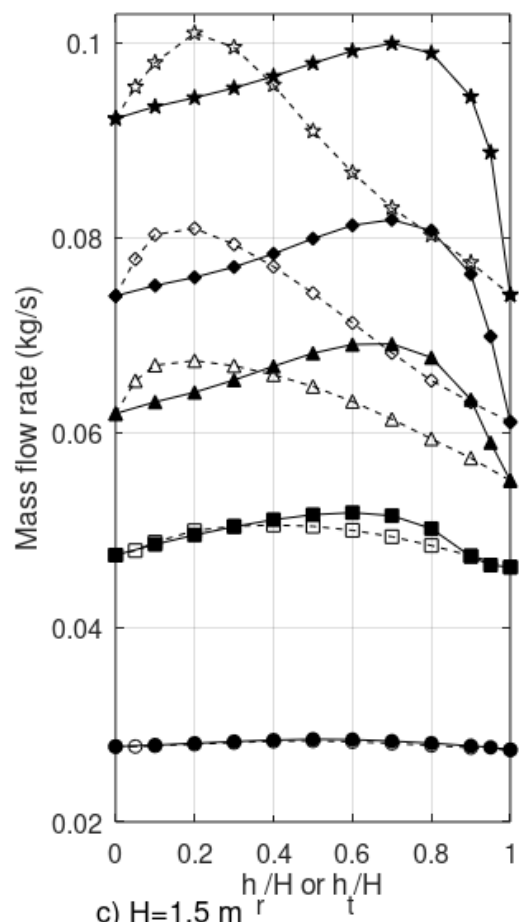

c) $\mathrm{H}=1.5 \mathrm{~m}^{\mathrm{r}}$

Fig. 4 Induced mass flow rate through the chimneys 


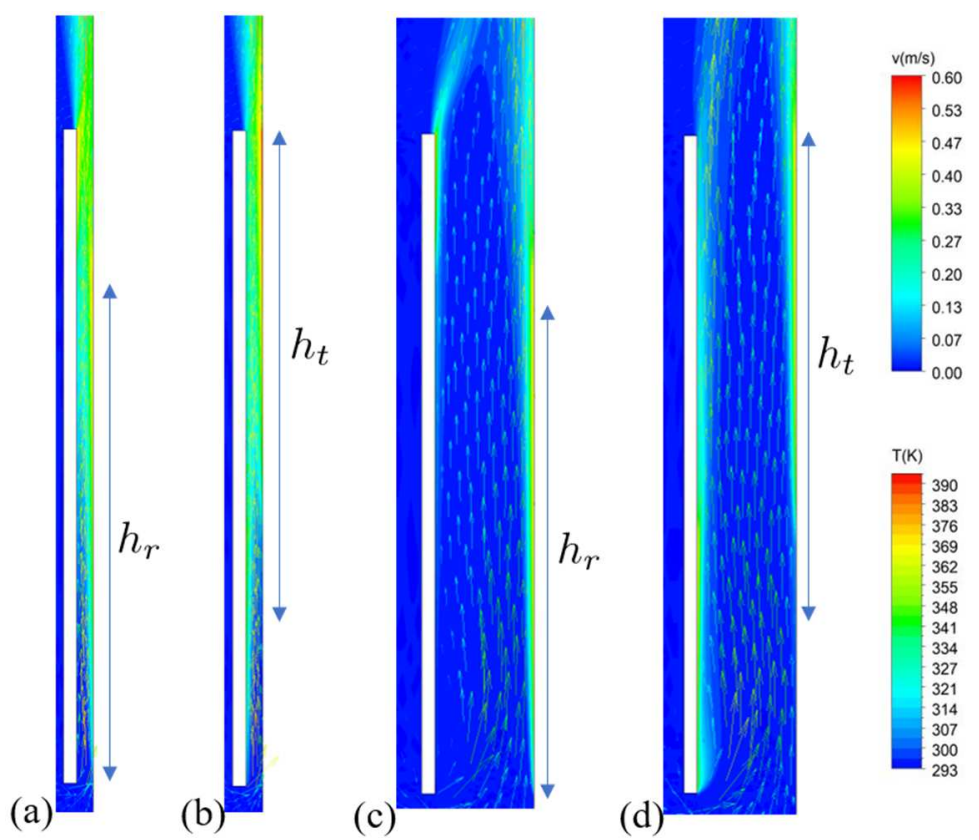

Fig. 5 Flow and temperature fields for $\mathrm{H}=0.5 \mathrm{~m}$ : (a) $\mathrm{G} / \mathrm{H}=0.025, h_{r} / H=0.8$; (b) $\mathrm{G} / \mathrm{H}=0.025, h_{t} / H=0.8 ;(\mathrm{c}) \mathrm{G} / \mathrm{H}=0.15, h_{r} / H=0.8$; and (d) $\mathrm{G} / \mathrm{H}=0.15$,
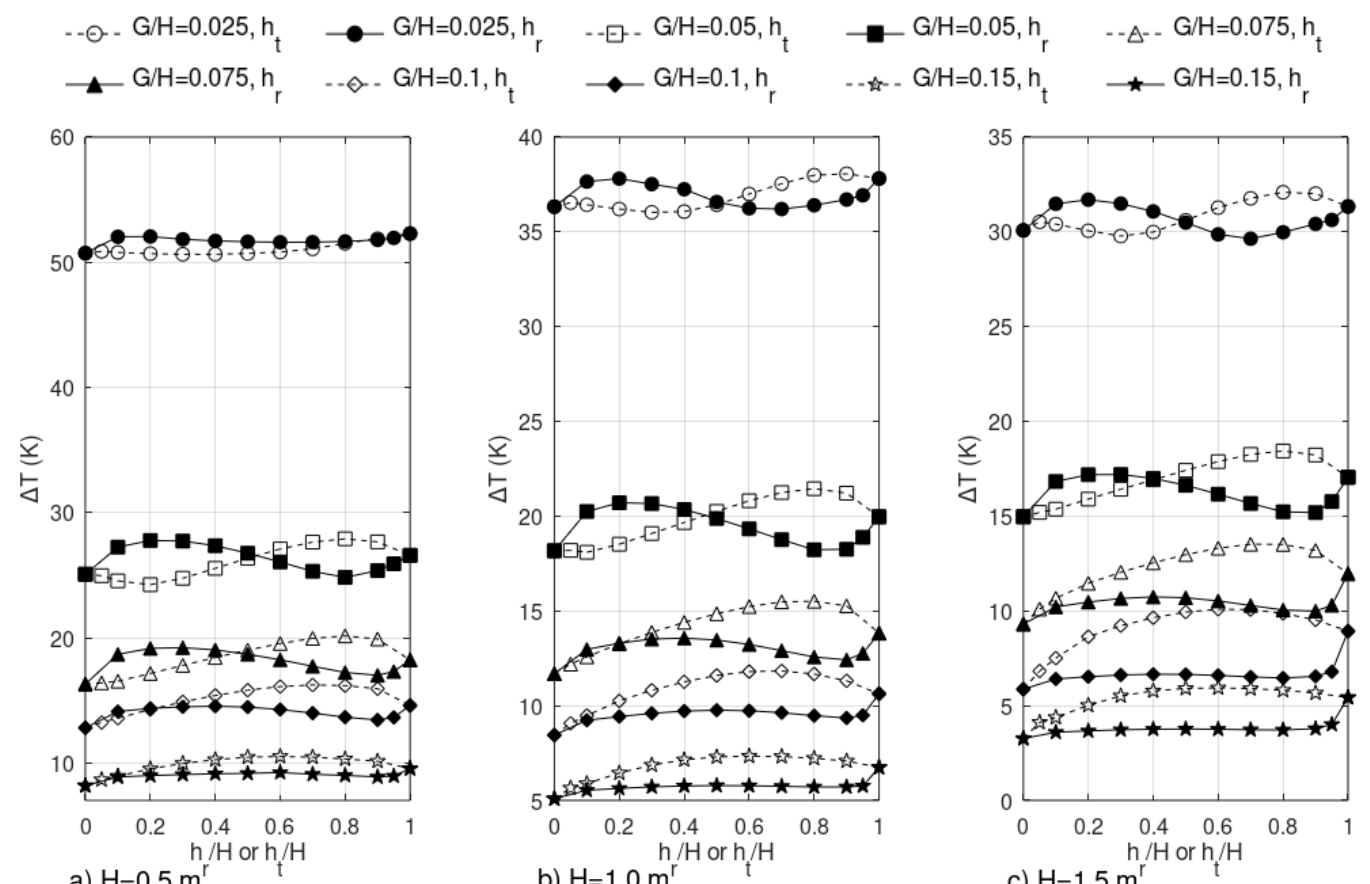

Fig. 6 Temperature rise through the chimneys

\section{Thermal Efficiency}

Thermal efficiency has been used to evaluate the performance of solar chimneys [17,25]. It is defined as the ratio between the heat gain of the airflow through the air channel $Q_{o}$ and the heat supplied in the air channel $Q_{i}$ :

$$
\eta=\mathrm{Qo} / \mathrm{Qi}=\dot{\mathrm{mcp}} \Delta \mathrm{T} / \mathrm{Qi}
$$

where $\dot{m}$ is the induced mass flow rate, and $\mathrm{c}_{\mathrm{p}}$ is the specific heat capacity of air.

Figure 7 presents the thermal efficiency $\eta$ of the tested chimneys. In general, $\eta$ changed significantly with $h_{r} / H$ and $h_{t} / H$, except for $\mathrm{G} / \mathrm{H}=0.025$ where it was almost constant and varied slightly about 0.95 .

At a given $\mathrm{H}, \eta$ decreased with the increase of $\mathrm{G} / \mathrm{H}$. From Figure $4, \dot{m}$ increased with $\mathrm{G} / \mathrm{H}$. However, in Figure $6, \Delta T$ decreased with $\mathrm{G} / \mathrm{H}$. For example, for $\mathrm{H}=0.5 \mathrm{~m}$, changing $\mathrm{G} / \mathrm{H}$ from 0.05 to 0.1 increased the average flow rate from $0.013 \mathrm{~kg} / \mathrm{s}$ to $0.017 \mathrm{~kg} / \mathrm{s}$ (Figure 4) but reduced the temperature rise from about $26 \mathrm{~K}$ to about $14.5 \mathrm{~K}$ (Figure 6). Therefore, the decreasing rate of $\Delta T$ was more than the increasing rate of $\dot{m}$ and equation (5) resulted in a decrease of $\eta$ with $\mathrm{G} / \mathrm{H}$

At a given $\mathrm{G} / \mathrm{H}$, increasing the chimney height offered lower thermal efficiency. This trend is seen in both cases of 
heating. Comparing $\eta$ of heating from the bottom, $h_{r}$, to heating from the top, $h_{t}$, the latter had higher thermal efficiency at higher $\mathrm{G} / \mathrm{H}$ ratios. As the $\mathrm{G} / \mathrm{H}$ ratio decreased, the difference of $\eta$ between the two heating cases was negligible. This result is consistent with the trends of the data in Figure 4 and 6.

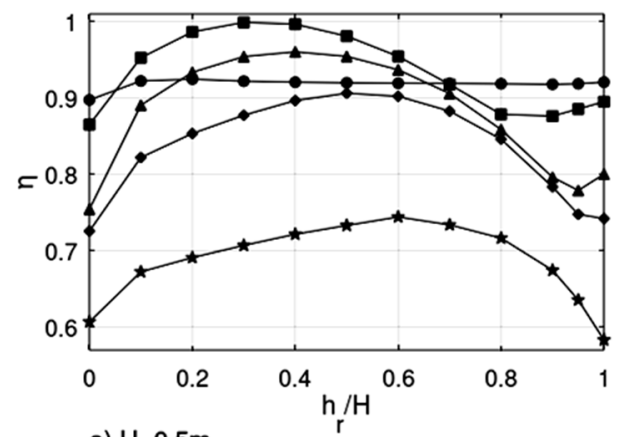

a) $\mathrm{H}=0.5 \mathrm{~m}$
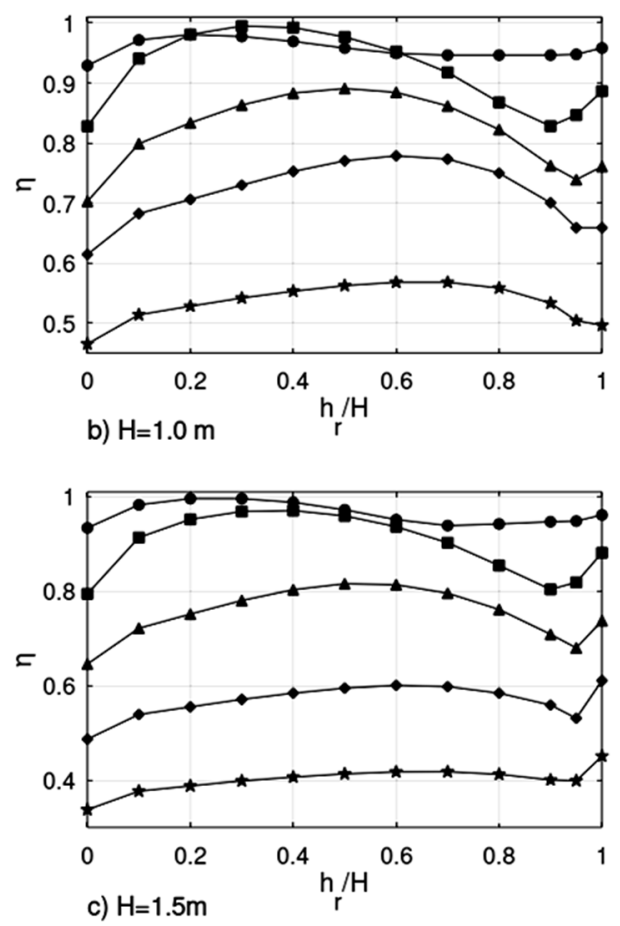

Heating the whole right wall $\left(h_{r} / H=h_{t} / H=1.0\right)$ offered slightly higher thermal efficiency than heating the whole left wall $\left(h_{r} / H=h_{t} / H=0\right)$. The peaks of the thermal efficiency in Figure 7 also changed with the $\mathrm{G} / \mathrm{H}$ ratio. As $\mathrm{G} / \mathrm{H}$ increased, the peak moved toward higher $h_{r} / H$ but to smaller $h_{t} / H$. Particularly, at $\mathrm{G} / \mathrm{H}=0.05$, the peak thermal efficiencies were close to 1.0 at $h_{r} / H \approx 0.3$ and $h_{t} / H \approx 0.7$.
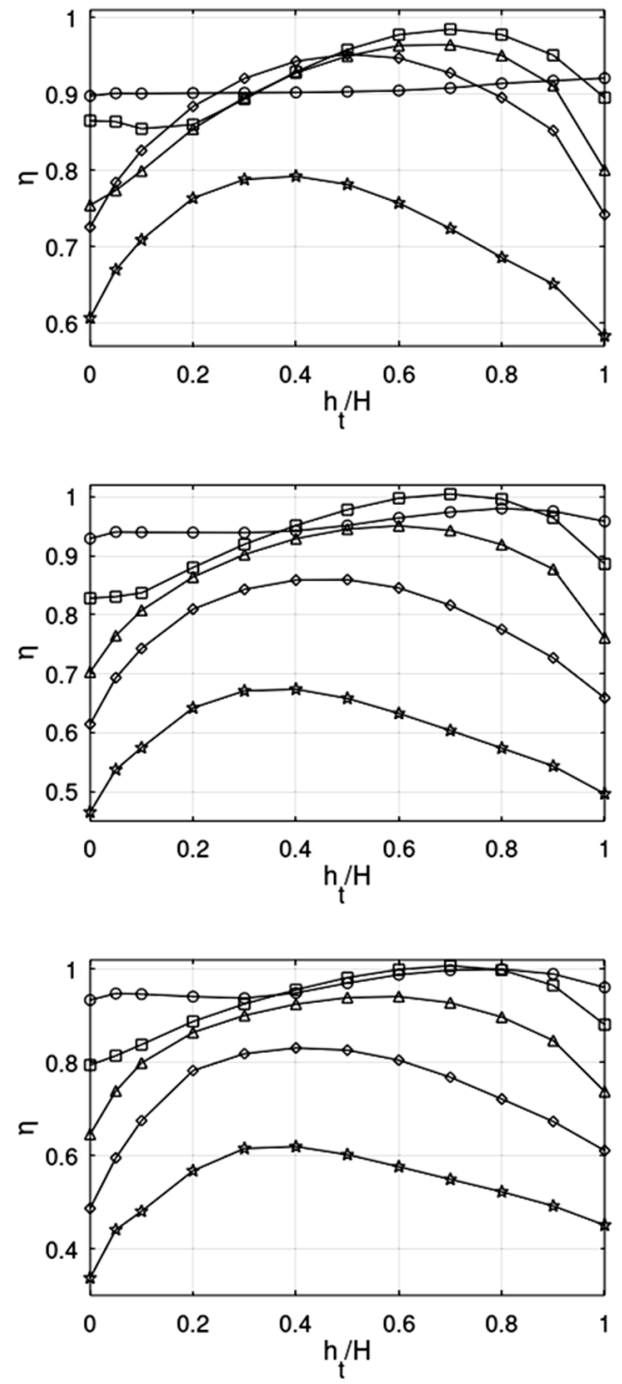

Fig. 7 Thermal efficiency of the solar chimneys

\section{CONCLUSION}

The results show that, together with the solar chimney dimensions, the heat source's location and distribution in the air channel also strongly affected its performance. When the heat source was distributed on a whole wall of the air channel, heating the left wall (Figure 1a) induced more flow rate. Heating part of the right and the left walls resulted in identical flow rates at the low gap-to-height ratio. As the gap-to-height ratio increased, heating the lower part of the right wall achieved the highest flowrate at $h_{r} / H \approx 0.7$. The peak flow rate for heating the upper part of the right wall was at $h_{t} / H \approx 0.2$. Two heating cases resulted in the same flow rate at $h_{r} / H=h_{t} / H$ $\approx[0.35-0.4]$.
While the induced flow rate increased with the gap-toheight ratio, the temperature rises through the chimney and the thermal efficiency decreased. As the gap-to-height ratio increased, heating the upper part of the right wall offered higher temperature rise and thermal efficiency. With a higher gap-to-height ratio, the thermal efficiency peak values moved toward higher $h_{r} / H$ but smaller $h_{t} / H$. Significantly, the highest thermal efficiencies were close to 1.0 at the gap-to-height ratio of 0.05 and $h_{r} / H \approx 0.3$ or $h_{t} / H \approx 0.7$.

As this study was conducted in two dimensions, for future works, three - dimensional simulations or experiments can be conducted to investigate effects of the sidewalls, particularly with different heat source distributions on the sidewalls, on the performance of the chimney. 


\section{REFERENCES}

[1] F. Pomponi, P. A. E. Piroozfar, R. Southall, P. Ashton, and R. P. Farr Eric, "Energy performance of Double-Skin Façades in temperate climates: A systematic review and meta-analysis", Renewable and Sustainable Energy Reviews, vol. 54, pp. 1525-1536, 2016.

[2] A. Al Touma and D. Ouahrani, "Performance assessment of evaporatively-cooled window driven by solar chimney in hot and humid climates", Solar Energy, vol. 169, pp. 187-195, 2018.

[3] A. M. Qahtan, "Thermal performance of a double-skin façade exposed to direct solar radiation in the tropical climate of Malaysia: A case study", Case Studies in Thermal Engineering, vol. 14, pp. 100419, 2019

[4] G. Gan, "Simulation of buoyancy-induced flow in open cavities for natural ventilation", Energy and Buildings, vol. 38(5), pp. 410-420, 2006.

[5] N. K. Bansal, R. Mathur, and M. S. Bhandari, "Solar chimney for enhanced stack ventilation", Building and Environment, vol. 28(3), pp. 373-377, 1993.

[6] O. Saadatian, C. H. Lim, K. Sopian, and E. Salleh, "A state of the art review of solar walls: Concepts and applications", Journal of Building Physics, vol. 37, pp. 55-79, 2013.

[7] L. Shi, G. Zhang, W. Yang, D. Huang, X. Cheng, and S. Setunge, "Determining the influencing factors on the performance of solar chimney in buildings", Renewable and Sustainable Energy Reviews, vol. 88, pp. 223-238, 2018.

[8] J. Mathur, S. Mathur, and Anupma, "Summer-performance of inclined roof solar chimney for natural ventilation", Energy and Buildings, vol. 38(10), pp. 1156-1163, 2006.

[9] K. S. Ong, "A mathematical model of a solar chimney", Renewable Energy, vol. 28, pp. 1047 - 1060, 2003.

[10] E. M. A. Mokheimer, M. R. Shakeel, and J. Al-Sadah, “A novel design of solar chimney for cooling load reduction and other applications in buildings", Energy and Buildings, vol. 153, pp. 219-230, 2017.

[11] N. Dimassi and L. Dehmani, "Performance comparison between an improved and a classical Trombe wall: An experimental study", Journal of Building Physics, vol. 40, pp. 372-395, 2017.

[12] I. Zavala-Guillén, J. Xamán, I. Hernández-Pérez, I. Hernández-Lopéz, M. Gijón-Rivera, and Y. Chávez, "Numerical study of the optimum width of 2a diurnal double air-channel solar chimney", Energy, vol. 147, pp. 403-417, 2018.
[13] A. C. Briga Sá, A. Martins, J. Boaventura-Cunha, J. Carlos Lanzinha, and A. Paiva, "An analytical approach to assess the influence of the massive wall material, thickness and ventilation system on the Trombe wall thermal performance", Journal of Building Physics, vol. 41, pp. 445-468, 2018

[14] H. H. Al-Kayiem, K. V. Sreejaya, and A. O. Chikere, "Experimental and numerical analysis of the influence of inlet configuration on the performance of a roof top solar chimney", Energy and Buildings, vol. 159, pp. 89-98, 2018.

[15] H. Wang and C. Lei, "Theoretical modeling of combined solar chimney and water wall for buildings", Energy and Buildings, vol. 187, pp. 186-200, 2019.

[16] Y. Q. Nguyen and J. C. Wells, “A numerical study on induced flowrate and thermal efficiency of a solar chimney with horizontal absorber surface for ventilation of buildings", Journal of Building Engineering, vol. 28, pp. 101050, 2020.

[17] Y. Q. Nguyen and J. C. Wells, "Effects of wall proximity on the airflow in a vertical solar chimney for natural ventilation of dwellings", Journal of Building Physics, vol. 44(3), pp. 1-26, 2020.

[18] G. Gan, "Impact of computational domain on the prediction of buoyancy-driven ventilation cooling", Building and Environment, vol. 45(5), pp. 1173-1183, 2010.

[19] J. H. Ferziger and M. Peric, Computational methods for fluid dynamics, New York: Springer-Verlag Berlin Heidelberg, 2002.

[20] B. Zamora and A. S. Kaiser, "Thermal and dynamic optimization of the convective flow in Trombe Wall shaped channels by numerical investigation", Applied Thermal Engineering, vol. 29(4), pp. 762-769, 2009.

[21] R. Bassiouny and N. S. A. Koura, "An analytical and numerical study of solar chimney use for room natural ventilation", Energy and Buildings, vol. 40(5), pp. 865-873, 2008.

[22] V. Yakhot and S. A. Orszag, "Renormalization group analysis of turbulence. I. Basic theory", Journal of Scientific Computing, vol. 1(1), pp. 3-51, 1986.

[23] T. Yilmaz and S. M. Fraser, "Turbulent natural convection in a vertical parallel-plate channel with asymmetric heating", International Journal of Heat and Mass Transfer, vol. 50(13-14), pp. 2612-2623, 2007.

[24] Fluent Inc., FLUENT user's guide, New Hampshire, USA, 2005.

[25] S. A. M. Burek and A. Habeb, "Air flow and thermal efficiency characteristics in solar chimneys and Trombe Walls", Energy and Buildings, vol. 39(2), pp. 128-135, 2007. 